\title{
The Smc complexes in DNA damage response
}

\author{
Nan Wu and Hongtao Yu ${ }^{*}$
}

\begin{abstract}
The structural maintenance of chromosomes (Smc) proteins regulate nearly all aspects of chromosome biology and are critical for genomic stability. In eukaryotes, six Smc proteins form three heterodimers-Smc1/3, Smc2/4, and Smc5/6-which together with non-Smc proteins form cohesin, condensin, and the Smc5/6 complex, respectively. Cohesin is required for proper chromosome segregation. It establishes and maintains sister-chromatid cohesion until all sister chromatids achieve bipolar attachment to the mitotic spindle. Condensin mediates chromosome condensation during mitosis. The Smc5/6 complex has multiple roles in DNA repair. In addition to their major functions in chromosome cohesion and condensation, cohesin and condensin also participate in the cellular DNA damage response. Here we review recent progress on the functions of all three Smc complexes in DNA repair and their cell cycle regulation by posttranslational modifications, such as acetylation, phosphorylation, and sumoylation. An in-depth understanding of the mechanisms by which these complexes promote DNA repair and genomic stability may help us to uncover the molecular basis of genomic instability in human cancers and devise ways that exploit this instability to treat cancers.
\end{abstract}

Keywords: Cohesin, Condensin, Smc5, Smc6, homologous recombination, DNA repair, DNA damage checkpoint, rDNA, SUMO

\section{Introduction}

The highly conserved structural maintenance of chromosomes (Smc) proteins regulate chromosome architecture and organization from bacteria to human. Most prokaryotes have a single Smc protein which forms a homodimer, while there are at least six Smc family members, Smc1-6, that form three heterodimers in eukaryotic organisms [1] (Figure 1). Smc1 and Smc3 form the core of the cohesin complex which maintains sister-chromatid cohesion during mitosis to ensure accurate chromosome segregation [2]. Smc2 and Smc4 constitute the condensin complexes that promote chromosome condensation [3]. Smc5 and Smc6 form a complex that plays critical roles in DNA repair $[4,5]$.

The Smc proteins contain about 1,000 amino acids and share similar domain structures. The ATPase domain of each Smc protein is separated into N- and Cterminal halves by a long linker. The two nucleotidebinding Walker $\mathrm{A}$ and Walker B motifs reside in the two different ATPase halves. The Smc linker folds into an intramolecular antiparallel coiled coil and allows the

\footnotetext{
* Correspondence: hongtao.yu@utsouthwestern.edu

* Correspondence: hongtao.yu@utsouthwestern.edu Park Road, Dallas, TX 75390, USA
}

N-terminal ATPase half of an Smc protein to fold back to its C-terminal ATPase half and create a single globular ATPase head (Figure 1). The hinge domain at one end of the coiled coil mediates the heterodimerization of eukaryotic Smc proteins [1,6,7]. The two ATPase heads at the other end of the coiled coil can transiently interact with each other to bind and hydrolyze ATP. As revealed by electron microscopy, the Smc heterodimers can adopt different conformations, including V-shaped dimer and ring-like structures, possibly depending on the nucleotide-binding states of their ATPase heads $[8,9]$. Each Smc heterodimer associates with non-Smc subunits to form functional Smc complexes.

The genomic DNA with a cell experiences many types of damage daily. These damages can result from exogenous factors, such as ultraviolet (UV) radiation, ionizing radiation (IR), and chemical carcinogens, or from endogenous factors, such as stalled replication forks due to replication stress. In response to DNA damage, cells elicit elaborate DNA damage responses. For example, DNA damage checkpoints arrest cell cycle progression at various points, thus affording more time for cells to execute DNA repair. Failure to properly repair DNA damage can result in cell death or genomic instability which may eventually lead to cancer [10]. 


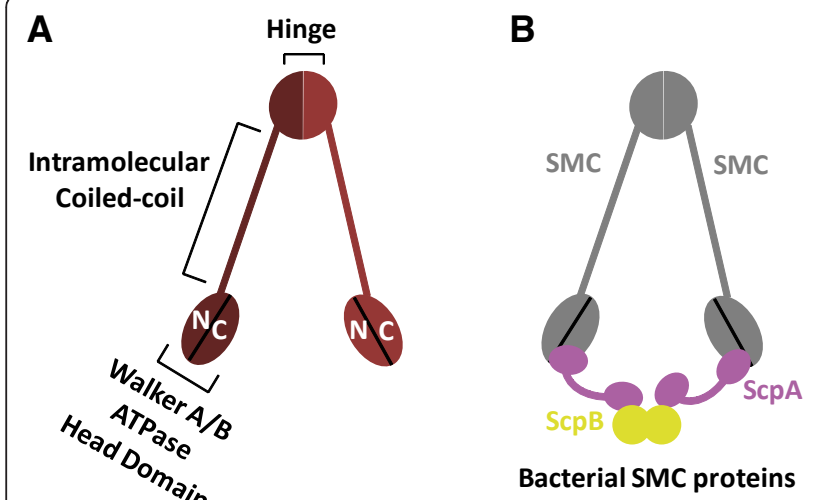

(i)

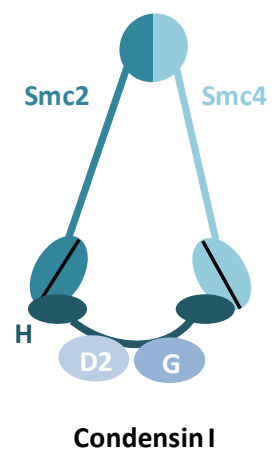

(iv)



(ii)

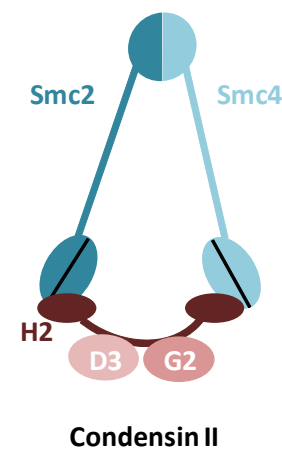

( $v$ )

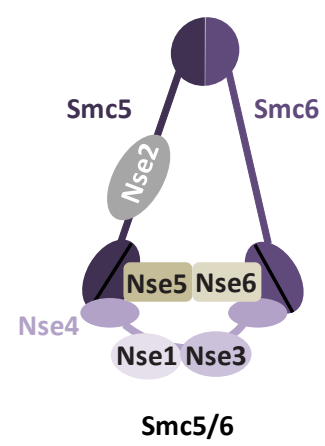

(iii)



Dosage compensation complex

(vi)

Figure 1 Architecture of the Smc complexes. (A) The core of each Smc complex is formed by two Smc proteins. Each Smc protein contains an ATPase head domain, a hinge domain, and an intramolecular antiparallel coiled coil that connects the two. The hinge domain mediates the dimerization of Smc proteins. (B) Various Smc complexes found in bacteria and eukaryotes. Each Smc complex is composed of a specific Smc dimer and several non-Smc subunits. (i) The bacterial Smc complex from Bacillus subtilis. ScpA connects the two ATPase heads of the Smc homodimer. (ii) The Smc1/3 cohesin complex. (iii) The Smc5/6 complex. (iv) The condensin I complex. H, D2, and G stand for CAP-H, CAP-D2, and CAP-G, respectively. (v) The condensin II complex. H2, D3, and G2 stand for CAP-H2, CAP-D3, and CAP-G2, respectively. (vi) The condensinlike dosage compensation complex in C. elegans. DPY-27 is an Smc4 variant.

The role of the Smc5/6 complex in DNA repair has long been appreciated. Emerging evidence in recent years has established that, in addition to their fundamental roles in chromosome segregation and organization, cohesin and condensin are also required for DNA damage checkpoints and DNA repair. In this review, we summarize the roles of these three Smc complexes in DNA damage response and the maintenance of genomic stability. We note that Rad50 is structurally related to the Smc proteins and has well-established roles in DNA repair as a subunit of the Mre11-Rad50-Nbs1 (MRN) complex. Because the MRN complex has been the subject of recent reviews [11], we will not focus on it in the current review.

\section{The Smc1/3 cohesin complex}

The cohesin complex is composed of four evolutionarily conserved subunits, Smc1, Smc3, and two non-Smc proteins named Scc1 and Scc3 [1,12] (Table 1). Vertebrate cells contain two Scc3 proteins, called SA1 and SA2. The $\mathrm{N}$ - and C-terminal regions of Scc1 link the head domains of Smc3 and Smc1, respectively, forming a tripartite ring. Scc3 is predicted to be a HEAT repeat-containing protein and interacts with Scc1 to further strengthen the ring structure of cohesin. Cohesin has been proposed to topologically embrace DNA and chromatids inside its ring. Other cohesin-binding proteins include Wapl, Pds5, and sororin (in metazoans) that associate with cohesin in a sub-stoichiometric manner. Their interactions with cohesin are regulated during the cell cycle. Wapl negatively regulates cohesin association with chromatin while sororin stabilizes cohesin on chromatin. Pds5 appears to have dual functions in cohesin regulation.

\subsection{Cohesin and sister-chromatid cohesion}

The major function of cohesin, as its name indicates, is to regulate sister-chromatid cohesion. Cohesin is loaded 
Table 1 Components of the Smc complexes and regulatory proteins in different organisms

\begin{tabular}{|c|c|c|c|}
\hline & S. cerevisiae & S. pombe & H. sapiens \\
\hline \multirow[t]{4}{*}{ Cohesin } & Smc1 & Psm1 & Smc1 \\
\hline & Smc3 & Psm3 & Smc3 \\
\hline & Mcd1/Scc1 & $\operatorname{Rad} 21$ & Scc1/Rad21 \\
\hline & IRR1/Scc3 & Psc3 & SA1/STAG1,SA2/STAG2 \\
\hline \multirow{6}{*}{$\begin{array}{l}\text { Cohesin } \\
\text { regulators }\end{array}$} & $\mathrm{Scc} 2$ & Mis4 & NIPBL \\
\hline & $\operatorname{Scc} 4$ & Ssl3 & MAU2/Scc4 \\
\hline & Ecol/Ctf7 & Esol & $\begin{array}{l}\mathrm{EFO1/ESCO1,EFO2/} \\
\mathrm{ESCO} 2\end{array}$ \\
\hline & $\mathrm{Pds5}$ & Pds5 & Pds5A, Pds5B \\
\hline & Rad61 & Wpl1 & Wapl \\
\hline & - & - & Sororin \\
\hline \multirow[t]{8}{*}{ Condensins } & Smc2 (I\&\|ll) & Cut14 & CAP-E \\
\hline & Smc4 (I\&II) & Cut3 & CAP-C \\
\hline & Brn1 & Cnd2 & CAP-H (I) \\
\hline & $Y \operatorname{cs} 4$ & Cnd1 & CAP-D2 (I) \\
\hline & $Y \operatorname{cs} 5$ & Cnd3 & CAP-G (I) \\
\hline & - & - & CAP-D3 (II) \\
\hline & - & - & CAP-G2 (II) \\
\hline & - & - & CAP-H2 (II) \\
\hline \multirow[t]{8}{*}{$\begin{array}{l}\text { The Smc5/6 } \\
\text { complex }\end{array}$} & Smc5 & $\begin{array}{l}\text { Spr18/ } \\
\text { Smc5 }\end{array}$ & Smc5 \\
\hline & Rhc18/Smc6 & $\begin{array}{l}\text { Rad18/ } \\
\text { Smc6 }\end{array}$ & Smc6 \\
\hline & Nse1 & Nse1 & Nse1 \\
\hline & Mms21/Nse2 & Nse2 & Nse2 \\
\hline & $\begin{array}{l}\text { YDR228W/ } \\
\text { Nse3 }\end{array}$ & Nse3 & Nse3 \\
\hline & Qri2/Nse4 & $\begin{array}{l}\text { Rad62/ } \\
\text { Nse4 }\end{array}$ & Nse4 \\
\hline & $\begin{array}{l}\text { YML023C/ } \\
\text { Nse5 }\end{array}$ & Nse5 & - \\
\hline & Kre29/Nse6 & Nse6 & - \\
\hline
\end{tabular}

by the cohesin loader Scc $2 / 4$ complex in telophase and G1 prior to DNA replication. The loaded cohesin then becomes cohesive during DNA replication and has been proposed to topologically embrace both sister chromatids inside its ring to establish sister-chromatid cohesion. The mechanism by which cohesin is converted to the cohesive state during DNA replication is not completely understood, but it requires the acetylation of Smc3 by the Eco1 family of acetyltransferases [13-16]. In vertebrates, Smc3 acetylation enables the binding of sororin to Pds5, which counteracts Wapl's ability to remove cohesin from chromatin [17-19]. Because sororin homologs have not been found in yeast, how Smc3 acetylation makes cohesin refractory to Wapl in yeast remains to be determined.
Timely dissolution of sister-chromatid cohesion is required for proper chromosome segregation in mitosis. In yeast, cohesin is cleaved by the protease separase at the metaphase-anaphase transition to trigger sister-chromatid separation. In humans, most cohesin on chromatid arms is removed by Wapl in prophase, and this process is facilitated by Plk1-dependent phosphorylation of SA2 [20-22]. Only a small amount of cohesin remains associated with the centromeres and is protected from Wapl and Plk1 by the shugoshin-PP2A complex [23-25]. This centromeric pool of cohesin is cleaved by separase at metaphase to allow sister-chromatid separation [26].

\subsection{Cohesin and DNA repair}

In addition to its function in sister-chromatid cohesion, cohesin plays critical roles in DNA damage response (Figure 2). In fact, cohesin's role in DNA repair was discovered before the discovery of its function in sisterchromatid cohesion. The cohesin subunit Scc1 was first identified as Rad21, whose mutation rendered S. pombe cells hypersensitive to UV or IR [27,28]. Later studies further confirmed a role of cohesin in DNA repair in several organisms, including S. cerevisiae, chicken, and humans [29-33]. These studies further pinpointed a specific function of cohesin in DNA double-strand break (DSB) repair through homologous recombination (HR).

In $S$. cerevisiae, cohesin and its positive regulators, including Scc2, Pds5, and Eco1, are all required for DSB repair during G2 [29]. Thus, it is not the cohesin complex per se but rather damage-induced functional sisterchromatid cohesion that is required for DNA repair. Moreover, in addition to observing the expected premature sister-chromatid separation phenotype in a conditional Scc1-deficient chicken DT40 cell line, Sonoda et al. also observed a marked defect in DNA repair in these cells [30]. The Scc1-deficient cell line exhibited increased chromosome aberrations in S/G2 and a reduced frequency of sister-chromatid exchange (SCE). Finally, human cells with cohesin subunits depleted by RNA interference (RNAi) also exhibited DNA repair and SCE defects [32-34]. Taken together, these data establish a crucial role for cohesin in DSB repair through sisterchromatid HR during S/G2 phases of the cell cycle.

What is the function of cohesin in HR? HR-mediated DSB repair requires an undamaged DNA template. During the mitotic cell cycle, sister chromatids are the preferred template for HR, as HR between homologues may lead to the loss of heterozygosity. It is generally believed that sister-chromatid cohesion at or near a DSB helps to keep the DSB and the undamaged sister chromatid at close proximity, thereby promoting strand invasion and sister-chromatid HR. Although this notion makes intuitive sense, it remains to be formally tested experimentally. Consistent with a specific requirement 


- Promoting sister-chromatid HR
- Regulating DNA repair pathway
choice between HR and NHEJ
- Regulating HR template choice
between sisters and homologues
Figure 2 Functions of cohesin in DNA damage response during the cell cycle. The function of cohesin in promoting DSB repair through
sister-chromatid homologous recombination (HR) has been established in multiple organisms ranging from yeast to man. Most of the other
proposed functions are only demonstrated in specific organisms, and their evolutionary conservation needs to be further tested.
Independent of cohesion function
Scc1 phosphorylationtion activation

for cohesin in sister-chromatid HR, cohesin is not required for certain forms of HR in S. cerevisiae, including intrachromosomal gene conversion [35]. Cohesin is also not required for processes that occur in all forms HR, such as end resection and the formation of singlestrand DNA at DSBs. Furthermore, cohesin suppresses DNA damage-induced recombination between homologous chromosomes in yeast [36]. Finally, cohesin coordinates DSB repair pathway choice between HR and nonhomologous end joining (NHEJ) through interaction with the Rad52 pathway [31]. These results are consistent with a specific role of cohesin in sister-chromatid HR. It is possible that the elevation of NHEJ and HR between homologues seen in cohesin-deficient cells is simply due to repair pathway competition. Alternatively, cohesin may actively suppress NHEJ and HR between homologues through unknown mechanisms.

\subsection{Recruitment of cohesin to DSBs}

A direct role of cohesin in DNA repair is further supported by its recruitment to DSBs, which was shown by both immunofluorescence (IF) and chromatin immunoprecipitation (ChIP). First, the Yokomori group detected the recruitment of cohesin to laser-induced DNA damage sites in human cells [37]. A laser microbeam was used to create DNA damage at discrete sites in the cell, and the recruitment of DNA repair proteins to these sites was monitored by IF. Shortly after radiation, cohesin and the MRN component Mre11 were detected at these sites. The recruitment of cohesin to these DNA damage foci was limited to S/G2 phases of the cell cycle, and dependent on Mre11 and Rad50. Furthermore, Rad50 was co-immunoprecipitated with cohesin subunits from human cells in S/G2, supporting a model in which MRN recruits cohesin to DSBs.

The recruitment of cohesin to DSBs is further supported by ChIP studies in yeast and human cells $[34,35,38]$. In these cases, specific restriction endonucleases were used to cut defined sites in the genome to generate DSBs. In the study by the Koshland group [35], cohesin enrichment around a DSB was detected with ChIP in G2/M phases, but not in G1 phase, of the cell cycle in S. cerevisiae, and required Scc2/4. In addition, proteins with well-known functions in $\mathrm{HR}$, such as Mec1, Tel1, Rad53, Mre11, and $\gamma \mathrm{H} 2 \mathrm{~A}$, are all required for the establishment of the DSB-specific cohesin 
domain. In an accompanying study, the Sjögren group reported that cohesin was recruited to $50-\mathrm{kb}$ genomic regions flanking a DSB induced during $\mathrm{G} 2 / \mathrm{M}$ in yeast [38]. They also showed that Scc2/4 was necessary for cohesin accumulation and DNA repair. Curious of the molecular function of cohesin recruitment to DSBs, the authors designed an elegant experiment to test whether functional cohesion was generated after induction of DSB. Indeed, they showed that cohesin recruited to the DSB was able to establish sister-chromatid cohesion in G2 phase after DNA replication. Finally, using ChIP, our lab showed that cohesin was also recruited to an I-SceIinduced DSB in human cells [34]. Thus, cohesin recruitment to DSBs is a conserved process of the DNA damage response in organisms from yeast to man.

\subsection{DNA damage-induced sister-chromatid cohesion}

Both the Sjögren and Koshland groups found in yeast that DNA damage induced sister-chromatid cohesion not only at the DSB site but also throughout the genome after genome duplication in G2 $[39,40]$. This damage-induced (DI) cohesion was controlled by the DNA damage response factors (Mec1, Tel1, Mre11, and $\gamma \mathrm{H} 2 \mathrm{~A})$ and cohesin regulators (Scc2, Eco1, and Smc6), but was independent of DNA replication. Overexpression of Eco1, but not an Eco1 mutant lacking its acetyltransferase activity, bypassed the requirement for DSBs in DI-cohesion generation in G2/M [40]. These results suggested that the activity of Eco1 was limiting in undamaged G2/M cells, and DNA damage response reactivated its activity.

How does DNA damage response augment Eco1's activity after DNA replication? What is the upstream signal? Does the signal regulate Eco1 or its substrate? What is the Eco1 substrate? Excellent studies by the Koshland group began to answer these questions $[41,42]$. They showed that phosphorylation of the cohesin subunit Scc1 (also known as Mcd1) by Chk1 at S83 was critical for DI cohesion. Substitution of S83 to alanine (S83A) inhibited DI cohesion, while substitution of S83 to aspartic acid (S83D) to mimic phosphorylation generated cohesion during $\mathrm{G} 2 / \mathrm{M}$, even in absence of a DSB or Chk1. Functional Eco1 was, however, still required for cohesion in S83D cells. Moreover, genetic evidence suggested that K84 and K210 of Scc1 were the Eco1-dependent acetylation sites in response to the DSB. Mutation of these two lysines to glutamine to mimic acetylation bypassed the requirement for the DSB or the acetyltransferase activity of Eco1 in DI cohesion. Furthermore, Smc3 acetylation by Eco1 was uniquely required for S-phase cohesion, but not for DI cohesion. Both Smc3 acetylation and Scc1 acetylation appeared to counteract the function of Wapl to establish cohesion. Collectively, their results support a model in which phosphorylation of Scc1 at S83 by Chk1 makes Scc1 a better substrate for Eco1, which then acetylates K84 and K210 of Scc1 to establish DI cohesion (Figure 2). Eco1 thus has distinct substrates in S-phase cohesion and DI cohesion. Future biochemical experiments are needed to confirm the phosphorylation and acetylation of Scc1 in response to the DSB.

So far, direct evidence for DI cohesion is only available in budding yeast. Several lines of indirect evidence suggest that DI cohesion might be a conserved mechanism in higher organisms. First, the critical cohesion-establishment factor, sororin, is required for efficient DSB repair during G2 in HeLa cells [19]. Sororin RNAi cells showed a marked increase of DNA breaks, compared to control cells. In addition, decreased inter-sister-chromatid distances were observed after DSB induction in chicken DT40 cells, consistent with the establishment of DI cohesion [43]. Moreover, $\times$ rays enhanced sister-chromatid alignment in plants [44]. Finally, ChIP followed by deep sequencing (ChIP-seq) revealed that IR triggered an Esco1-dependent increase in Smc3 acetylation and a genome-wide reinforcement of cohesin binding at pre-existing sites in human cells [45].

Future experiments are obviously needed to firmly establish DI cohesion as a conserved mechanism during DNA damage response in all eukaryotes. Moreover, even if DI cohesion exists in higher eukaryotes, the posttranslational modifications that regulate DI cohesion might be different from that of yeast. For example, DNA damage-induced Scc1 acetylation could not be detected in human cells [45]. The sites of Scc1 acetylation are also not conserved in human Scc1.

\subsection{Cohesin and DNA damage checkpoint activation}

In addition to its direct role in HR repair, cohesin is involved in DNA damage checkpoint activation (Figure 2 ). Several studies established the role of cohesin in intra-S-phase checkpoint activation in human cells [46-49]. In response to DNA damage [e.g. IR, UV, and hydroxyurea (HU)], ATM or ATR phosphorylated two residues, S957 and S966, of Smc1, and phosphorylation of these two sites was required for S-phase checkpoint activation. In addition to Smc1, Smc3 was also phosphorylated by ATM at S1083 in response to IR, and S1083 phosphorylation was similarly required for the intra-S phase checkpoint [50]. The Smc1/3 functions in the intra-S checkpoint are apparently mediated by the intact cohesin, not through a separate Smc1/3-containing recombination complex [51].

How cohesin phosphorylation activates intra-S phase checkpoint to block DNA synthesis in response to DNA damage remains unclear at present and awaits the identification of the downstream effectors of Smc1/3 phosphorylation. These phosphorylation events may directly 
recruit proteins essential for checkpoint activation to damage sites. Alternatively, phosphorylation of cohesin may affect its dynamic association with chromatin through regulating the ATPase activities of Smc1/3. This in turn may allow cohesin to act as barriers on chromatin and directly slow down DNA replication. Regardless of the mechanism, cohesin's role in S-phase checkpoint activation highlights a two-way crosstalk between cohesin and DNA replication.

Recently, cohesin has also been implicated in the G2/M DNA damage checkpoint in human cells [51]. Depletion of Scc1, but not sororin, by RNAi caused defective 53BP1 recruitment to DNA damage foci and weaker Chk2 activation in G2. Because sororin is required for functional cohesion, this result suggested that the G2/M checkpoint function of cohesin could be uncoupled from its function in sister-chromatid cohesion. Consistent with this notion, cohesin was also required for Chk2 activation in G1 prior to DNA replication (Figure 2).

\subsection{Separase-mediated cohesin cleavage in DNA repair}

An interesting study in $S$. pombe implicated a requirement for cohesin cleavage by separase in DNA repair [52]. It was shown that the separase inhibitor securin was essential for the proper repair of DNA damage induced by UV and IR. Expression of a non-cleavable Scc1 or inactivation of separase impaired DNA repair during G2, suggesting that the DNA repair functions of securin and separase acted through the cleavage of cohesin. Whether cohesin cleavage by separase is required for DNA repair in other organisms remains to be determined. It is also unclear how separase becomes active in G2 and how its activity is presumably restricted to DNA damage sites.

\section{The Smc2/4 condensin complexes}

Condensin complexes are five-subunit complexes that regulate chromosome organization and condensation during mitosis and meiosis in eukaryotic cells. They are responsible for folding chromatin fibers into highly compact chromosomes to ensure their faithful segregation. In vertebrates, there are two types of condensin complexes: condensin I and condensin II [6] (Table 1). Condensins I and II share two core subunits, Smc2/ CAP-E and Smc4/CAP-C, but differ in the other three non-Smc subunits. Condensin I contains CAP-D2, CAP$\mathrm{H}$, and CAP-G while condensin II contains CAP-D3, CAP-H2, and CAP-G2 [53] (Figure 1). The two condensin complexes have apparently different roles in chromosome organization [54]. Depletion of condensin I produces a swollen chromosome shape while depletion of condensin II produces a curly shape. Depletion of both results in the formation of cloud-like chromosomes with a fuzzy appearance. In addition to condensins I and
II, C. elegans has a specialized condensin-like Smc complex that regulates dosage compensation. This complex is composed of Smc2, an Smc4 variant called DPY-27, and three non-Smc proteins, DPY-26, DPY-28, and CAPG-1 [3,55].

\subsection{Condensins in checkpoint activation and DNA repair}

The first finding to reveal condensin's role in DNA repair came from a study in S. pombe [56]. In this study, Aono et al. isolated a temperature-sensitive mutant of cnd2, a non-Smc subunit in the condensin complex [56]. In addition to the expected mitotic chromosome condensation defects, this mutant exhibited elevated sensitivity to UV, HU, and methyl methanesulfonate (MMS), and a defect in Cds1 (the fission yeast ortholog of Chk2) activation. These results established a role of condensin in the replication checkpoint control and DNA repair. In a subsequent study, the same group identified a new condensin-binding protein called Cti1, using the hinge domain of Cut3 (Smc4) as the bait in a yeast two-hybrid screen [57]. Overexpression of Cti1 suppressed the UV and HU sensitivity of the Cnd2 mutant, suggesting that Cti1 positively regulated the DNA repair function of condensin.

The two condensin complexes in humans are also involved in DNA repair. Condensin I has been shown to play a role in DNA single-strand break (SSB) repair by interacting with the PARP1-XRCC1 complex [58,59]. Condensin I does not appear to play a significant role in DSB repair. By contrast, a recent study showed that condensin II was involved in HR repair of DSBs to maintain genome integrity [60]. Furthermore, depletion of condensin II only affected HR repair of IR-induced DSBs, but not the activation of the G2/M checkpoint.

\subsection{Condensins and rDNA stability}

Aside from its direct role in DNA repair to maintain genomic stability, condensin prevents unwanted intrachromosomal HR at the rDNA locus and controls rDNA stability in yeast [61-63]. Condensin regulates rDNA condensation during interphase upon nutrient starvation. This sub-chromosomal DNA compaction likely inhibits intrachromosomal $\mathrm{HR}$ at this locus, reduces the production of extrachromosomal rDNA circles, and protects the integrity of the rDNA array. In the absence of condensin, Rad52 improperly localizes to the nucleolus. Deletion of Rad52 rescues the cell lethality under nutrient starvation caused by condensin inactivation. Thus, condensin-dependent nucleolus exclusion of Rad52 provides one mechanism for the regulation of rDNA stability by condensin.

rDNA stability is critical for normal nucleolar function and ribosome biogenesis. Dysregulation of ribosome biogenesis has been linked to cancer and other human 
diseases. In the future, it will be important to determine whether the rDNA protection function of condensin is conserved in higher organisms, including humans. Along this vein, both Xenopus and human condensins have been shown to be associated with nucleolus during interphase $[64,65]$.

\section{The Smc5/6 complex}

Unlike cohesin and condensins which have other major non-DNA repair functions in chromosome biology, the Smc5/6 complex is primarily required for DNA repair. The Smc5/6 complex is composed of Smc5, Smc6, and several non-SMC elements (Nse), including Nse1-6 (Table 1). Nse4 bridges the ATPase head domains of Smc5 and Smc6 (Figure 1), possibly in a manner similar to the role of Scc1 in linking Smc1 and Smc3. Nse1 interacts with Nse3, and both Nse1 and Nse3 bind to Nse4. Mms21/Nse2 does not bind to the ATPase head domains of Smc5/6, but interacts with the coiled-coil region of Smc5 $[4,66]$. Intriguingly, two of the Nse proteins have enzymatic activities. Nse1 contains a RING domain commonly found in ubiquitin ligases and forms an active ubiquin ligase with the MAGE (melanomaassociated antigen gene) protein Nse3 [67]. Mms21 contains an SP-RING domain and has small ubiquitin-like modifier (SUMO) ligase activity [68-70]. The SUMO ligase activity of Mms21 has been shown to be crucial for DNA damage repair and targets several substrates in different organisms from yeast to man.

\subsection{The Smc5/6 complex and DSB repair by HR}

The $5 m c 6$ gene was initially identified by its ability to correct the radiation sensitivity of the rad18- $X$ mutant isolated in a screen for radiation-sensitive mutations in the fission yeast $S$. pombe $[27,71,72]$. Smc5 and Smc6 are essential genes in yeast. Hypomorphic alleles of the Smc5/6 complex exhibit defects in the repair of DNA damage caused by a broad spectrum of agents, including IR, UV, MMS, mitomycin C and HU [5,69,73-76]. In $S$. pombe, Smc6 is not only required for DSB repair induced by IR, but also is required for G2/M checkpoint activation [77]. Epistasis analysis further suggests a role of the Smc5/6 complex in HR, since rad18, nse1, and $n s e 2$ are epistatic with $r h p 51$ (the fission yeast $\operatorname{Rad} 51$, a key HR protein) in response to IR [72,78].

Consistent with these studies in the fission yeast, inactivation of the Smc5/6 complex in budding yeast, plants, chickens, and humans all results in sister-chromatid HR defects [34,44,79-81]. In keeping with the role of the Smc5/6 complex in HR, it is recruited to HO-induced DSBs in budding yeast and I-SceI-induced DSBs in human cells, as revealed by ChIP experiments $[34,80,82]$. Moreover, the Smc5/6 complex is only enriched at or around the HO-induced DSB in G2/M, but not in G1 when the sister chromatid is absent. Mre11, but not Mec1 and Rad53, are required for Smc6 recruitment to DSBs in yeast [82]. Similar to cohesin depletion, depletion of the Smc5/6 complex in human cells reduced SCE. Co-depletion of both cohesin and the Smc5/6 did not further reduce SCE, suggesting that they acted in the same pathway to promote sister-chromatid HR [34] (Figure 3). Future studies are required to address the mechanisms by which the Smc5/6 complex promotes HR between sister chromatids.

\subsection{The Smc5/6 complex and stalled replication forks}

A second function of the Smc5/6 complex in DNA repair is the repair of collapsed replication forks [83]. Smc6 localizes to collapsed replication forks in budding yeast [82]. Inactivation of Smc5/6 caused accumulation of X-shaped HR intermediates that could be formed by the regression of stalled replication forks in rDNA. Furthermore, the SUMO ligase activity of Mms21 is required for preventing the accumulation of the $\mathrm{X}$ shaped DNA molecules at damaged replication forks [84], although the relevant substrate of Mms21 in this process is unknown. Overexpression of BRC1 (a BRCT domain protein required for DNA repair during $S$ phase) or the bacterial resolvase RuvA rescued the replication-arresting defects of nse5, nse6, and smc6 mutants in $S$. pombe $[76,85,86]$. The structure-specific endonucleases Slx1/4 and Mus81/Eme1 are required for the BRC1-mediated suppression of Smc5/6 mutant phenotypes. Moreover, inactivation of the Mph1 helicase suppressed the accumulation of aberrant recombination intermediates in smc6 and mms $21 / n s e 2$ mutants in $S$. cerevisiae [87]. Smc5/6 has also been shown to facilitate the resolution of sister-chromatid linkages during mitosis $[88,89]$. Finally, the Smc5/6 complex is required for loading RPA and Rad52 onto stalled replication forks to maintain them in recombination-competent configurations [90]. Collectively, these investigations indicate that the Smc5/6 complex promotes HR-dependent rescue of stalled replication forks by stabilizing them in recombination-component configurations and by facilitating the resolution or preventing the formation of certain recombination intermediates (Figure 3).

\subsection{The Smc5/6 complex and rDNA integrity}

Similar to condensin, the Smc5/6 complex is required for the maintenance of rDNA stability in budding yeast (Figure 3). The Smc5/6 complex accumulates at rDNA regions in budding yeast [82]. It is enriched in the nucleolus [91]. Inactivation of Smc5 or the Mms21 SUMO ligase activity results in fragmented and irregularly shaped nucleoli $[70,92]$, indicating a role of the Smc5/6 complex in maintaining rDNA integrity. The repair of DSBs in the rDNA locus occurs outside the 


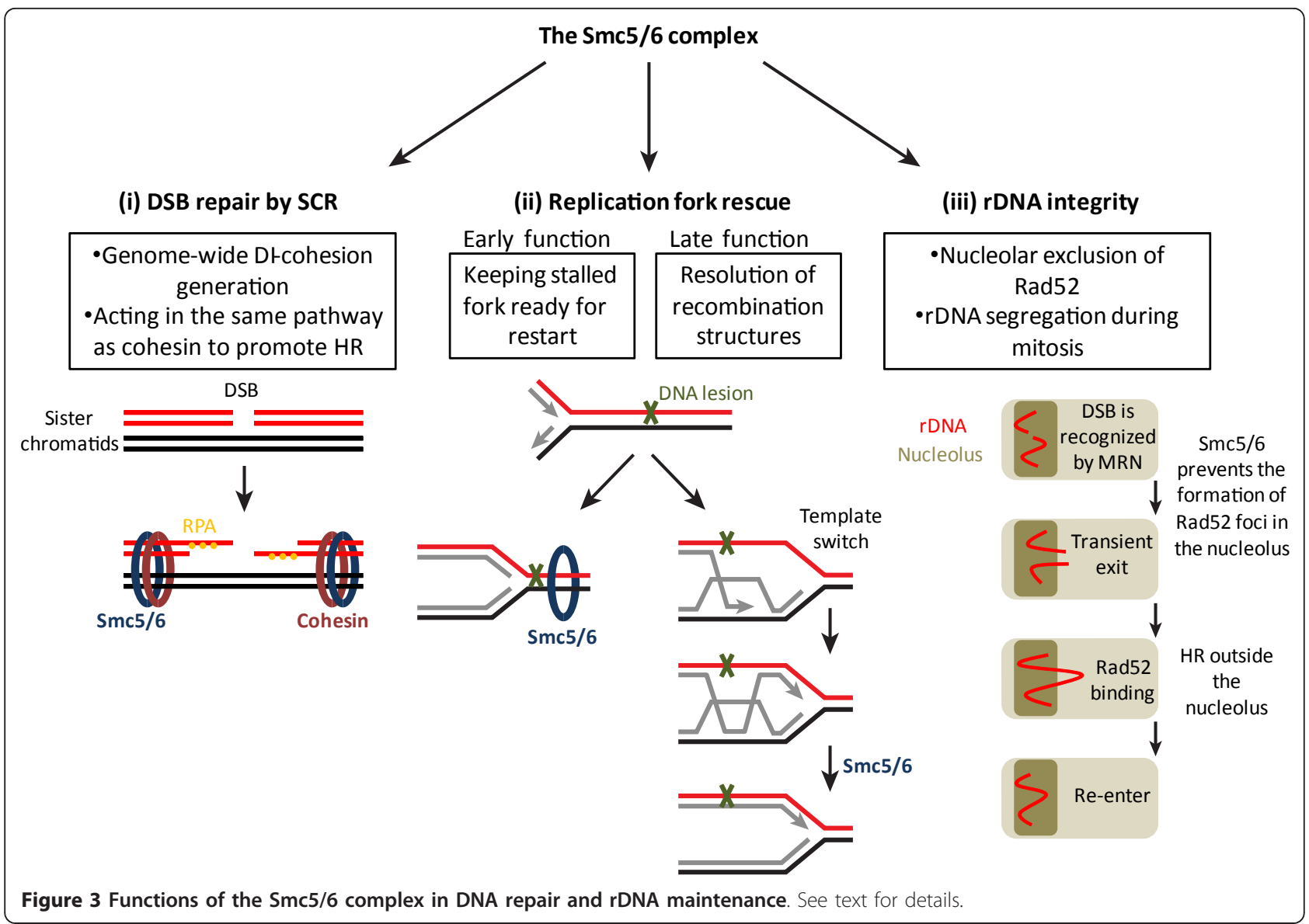

nucleolus. To preserve the repetitive sequence of the rDNA array, DSB recognition, end resection, and RPA binding happen within the nucleolus. On the other hand, binding of the key downstream HR proteins Rad51 and Rad52 to these DSBs are excluded from the nucleolus. Cells harboring mutations in the Smc5/6 complex exhibit Rad52 foci at the DSBs in the nucleolus and elevated numbers of extrachromosomal rDNA circles [93]. These findings suggest that the $S m c 5 / 6$ complex mediates the nucleolar exclusion of Rad52, thereby suppressing the recombinational loss of rDNA repeats to ensure rDNA stability (Figure 3).

\section{Conclusions}

The Smc family of proteins has critical roles in the DNA damage response of organisms from yeast to man. The Smc1/3 cohesin complex promotes DNA double-strand break (DSB) repair through homologous recombination (HR) between sister chromatids, presumably by holding sister chromatids in proximity to help strand invasion. Cohesin is also required for DNA damage checkpoint activation. The condensin complexes are required for DNA damage checkpoint activation, DNA repair, and rDNA stability. The Smc5/6 complex facilitates DSB repair through HR between sister chromatids and does so in the same pathway as cohesin. The Smc5/6 complex has additional roles in DNA repair, including resolution of collapsed replication forks and rDNA maintenance.

Many outstanding questions still remain in this area. First, the detailed molecular mechanisms by which the Smc proteins mediate DNA repair are not understood. In particular, in the cases of cohesin and condensin, it is unclear whether their DNA repair functions are separable from their major functions in sister-chromatid cohesion and chromosome condensation. Second, more needs to be learned about how the DNA repair functions of the Smc complexes are regulated during the cell cycle. Finally, the coordination and crosstalk among the three Smc complexes in the DNA damage response need to be further examined. Both cohesin and the Smc5/6 complex act in the same pathway to repair DSBs through HR between sister chromatids. How do they communicate with each other? Likewise, both condensin and the Smc5/6 complex are required for rDNA stability in yeast. Is this function of condensin and Smc5/6 conserved in higher eukaryotes? Do these two complexes function in the same or different pathways? 
Future studies aimed at addressing these questions will greatly advance our understanding of the molecular mechanisms underlying chromosome maintenance and genome stability.

Mutations of the Smc complexes and their regulators have been linked to human diseases, including cancer. A better understanding of how these complexes protect genomic stability will help us understand the molecular basis of disease phenotypes and may ultimately lead to strategies that exploit the dysregulation of the Smc proteins to treat these human diseases.

\section{Acknowledgements}

Research in our laboratory is supported in part by grants from Cancer Prevention and Research Institute of Texas and the Welch Foundation (I1441). HY is an Investigator with the Howard Hughes Medical Institute.

\section{Authors' contributions}

NW prepared the initial draft of the paper. HY modified and finalized the paper. All authors read and approved the final manuscript.

\section{Competing interests}

The authors declare that they have no competing interests.

Received: 7 December 2011 Accepted: 27 February 2012

Published: 27 February 2012

\section{References}

1. Losada A, Hirano T: Dynamic molecular linkers of the genome: the first decade of SMC proteins. Genes Dev 2005, 19:1269-1287.

2. Nasmyth K: Segregating sister genomes: the molecular biology of chromosome separation. Science 2002, 297:559-565.

3. Hirano T: Condensins: organizing and segregating the genome. Curr Biol 2005, 15:R265-275.

4. Potts PR: The Yin and Yang of the MMS21-SMC5/6 SUMO ligase complex in homologous recombination. DNA Repair (Amst) 2009, 8:499-506.

5. Lehmann AR: The role of SMC proteins in the responses to DNA damage. DNA Repair (Amst) 2005, 4:309-314.

6. Hirano T: At the heart of the chromosome: SMC proteins in action. Nat Rev Mol Cell Biol 2006, 7:311-322.

7. Nasmyth $\mathrm{K}$, Haering $\mathrm{CH}$ : The structure and function of SMC and kleisin complexes. Annu Rev Biochem 2005, 74:595-648.

8. Melby TE, Ciampaglio CN, Briscoe G, Erickson HP: The symmetrical structure of structural maintenance of chromosomes (SMC) and MukB proteins: long, antiparallel coiled coils, folded at a flexible hinge. J Cell Biol 1998, 142:1595-1604

9. Anderson DE, Losada A, Erickson HP, Hirano T: Condensin and cohesin display different arm conformations with characteristic hinge angles. J Cell Biol 2002, 156:419-424.

10. Sancar A, Lindsey-Boltz LA, Unsal-Kacmaz K, Linn S: Molecular mechanisms of mammalian DNA repair and the DNA damage checkpoints. Annu Rev Biochem 2004, 73:39-85.

11. Stracker TH, Petrini JH: The MRE11 complex: starting from the ends. Nat Rev Mol Cell Biol 2011, 12:90-103.

12. Onn I, Heidinger-Pauli JM, Guacci V, Unal E, Koshland DE: Sister chromatid cohesion: a simple concept with a complex reality. Annu Rev Cell Dev Biol 2008, 24:105-129.

13. Unal E, Heidinger-Pauli JM, Kim W, Guacci V, Onn I, Gygi SP, Koshland DE: A molecular determinant for the establishment of sister chromatid cohesion. Science 2008, 321:566-569.

14. Rolef Ben-Shahar T, Heeger S, Lehane C, East P, Flynn H, Skehel M, Uhlmann F: Eco1-dependent cohesin acetylation during establishment of sister chromatid cohesion. Science 2008, 321:563-566.

15. Zhang J, Shi X, Li Y, Kim BJ, Jia J, Huang Z, Yang T, Fu X, Jung SY, Wang Y, et al: Acetylation of Smc3 by Eco1 is required for $S$ phase sister chromatid cohesion in both human and yeast. Mol Cell 2008, 31:143-151.
16. Rowland BD, Roig MB, Nishino T, Kurze A, Uluocak P, Mishra A, Beckouet F Underwood P, Metson J, Imre R, et al: Building sister chromatid cohesion: smc3 acetylation counteracts an antiestablishment activity. Mol Cell 2009, 33:763-774,

17. Nishiyama T, Ladurner R, Schmitz J, Kreidl E, Schleiffer A, Bhaskara V, Bando M, Shirahige K, Hyman AA, Mechtler K, et al: Sororin mediates sister chromatid cohesion by antagonizing Wapl. Cell 2010, 143:737-749.

18. Rankin S, Ayad NG, Kirschner MW: Sororin, a substrate of the anaphasepromoting complex, is required for sister chromatid cohesion in vertebrates. Mol Cell 2005, 18:185-200.

19. Schmitz J, Watrin E, Lenart P, Mechtler K, Peters JM: Sororin is required for stable binding of cohesin to chromatin and for sister chromatid cohesion in interphase. Curr Biol 2007, 17:630-636.

20. Gandhi R, Gillespie PJ, Hirano T: Human Wapl is a cohesin-binding protein that promotes sister-chromatid resolution in mitotic prophase. Curr Biol 2006, 16:2406-2417.

21. Kueng S, Hegemann B, Peters BH, Lipp JJ, Schleiffer A, Mechtler K, Peters JM: Wapl controls the dynamic association of cohesin with chromatin. Cell 2006, 127:955-967.

22. Hauf S, Roitinger E, Koch B, Dittrich CM, Mechtler K, Peters JM: Dissociation of cohesin from chromosome arms and loss of arm cohesion during early mitosis depends on phosphorylation of SA2. PLOS Biol 2005, 3:e69.

23. Kitajima TS, Sakuno T, Ishiguro K, lemura S, Natsume T, Kawashima SA, Watanabe $Y$ : Shugoshin collaborates with protein phosphatase $2 \mathrm{~A}$ to protect cohesin. Nature 2006, 441:46-52.

24. Riedel CG, Katis VL, Katou Y, Mori S, Itoh T, Helmhart W, Galova M, Petronczki M, Gregan J, Cetin B, et al: Protein phosphatase 2A protects centromeric sister chromatid cohesion during meiosis I. Nature 2006, 441:53-61.

25. Tang Z, Shu H, Qi W, Mahmood NA, Mumby MC, Yu H: PP2A is required for centromeric localization of Sgo1 and proper chromosome segregation. Dev Cell 2006, 10:575-585.

26. Uhlmann F, Wernic D, Poupart MA, Koonin EV, Nasmyth K: Cleavage of cohesin by the $C D$ clan protease separin triggers anaphase in yeast. Cell 2000, 103:375-386.

27. Phipps J, Nasim A, Miller DR: Recovery, repair, and mutagenesis in Schizosaccharomyces pombe. Adv Genet 1985, 23:1-72.

28. Birkenbihl RP, Subramani S: Cloning and characterization of rad21 an essential gene of Schizosaccharomyces pombe involved in DNA doublestrand-break repair. Nucleic Acids Res 1992, 20:6605-6611.

29. Sjogren C, Nasmyth K: Sister chromatid cohesion is required for postreplicative double-strand break repair in Saccharomyces cerevisiae. Curr Biol 2001, 11:991-995.

30. Sonoda E, Matsusaka T, Morrison C, Vagnarelli P, Hoshi O, Ushiki T, Nojima K, Fukagawa T, Waizenegger IC, Peters JM, et al: Scc1/Rad21/Mcd1 is required for sister chromatid cohesion and kinetochore function in vertebrate cells. Dev Cell 2001, 1:759-770.

31. Schar P, Fasi M, Jessberger R: SMC1 coordinates DNA double-strand break repair pathways. Nucleic Acids Res 2004, 32:3921-3929.

32. Atienza JM, Roth RB, Rosette C, Smylie KJ, Kammerer S, Rehbock J, Ekblom J, Denissenko MF: Suppression of RAD21 gene expression decreases cell growth and enhances cytotoxicity of etoposide and bleomycin in human breast cancer cells. Mol Cancer Ther 2005, 4:361-368.

33. Bauerschmidt C, Arrichiello C, Burdak-Rothkamm S, Woodcock M, Hill MA, Stevens DL, Rothkamm K: Cohesin promotes the repair of ionizing radiation-induced DNA double-strand breaks in replicated chromatin. Nucleic Acids Res 2010, 38:477-487.

34. Potts PR, Porteus MH, Yu H: Human SMC5/6 complex promotes sister chromatid homologous recombination by recruiting the $\mathrm{SMC} 1 / 3$ cohesin complex to double-strand breaks. EMBO J 2006, 25:3377-3388.

35. Unal E, Arbel-Eden A, Sattler U, Shroff R, Lichten M, Haber JE, Koshland D: DNA damage response pathway uses histone modification to assemble a double-strand break-specific cohesin domain. Mol Cell 2004, 16:991-1002.

36. Covo S, Westmoreland JW, Gordenin DA, Resnick MA: Cohesin Is limiting for the suppression of DNA damage-induced recombination between homologous chromosomes. PLoS Genet 2010, 6:e1001006.

37. Kim JS, Krasieva TB, LaMorte V, Taylor AM, Yokomori K: Specific recruitment of human cohesin to laser-induced DNA damage. J Biol Chem 2002, 277:45149-45153. 
38. Strom L, Lindroos HB, Shirahige K, Sjogren C: Postreplicative recruitment of cohesin to double-strand breaks is required for DNA repair. Mol Cell 2004, 16:1003-1015.

39. Strom L, Karlsson C, Lindroos HB, Wedahl S, Katou Y, Shirahige K, Sjogren C: Postreplicative formation of cohesion is required for repair and induced by a single DNA break. Science 2007, 317:242-245.

40. Unal E, Heidinger-Pauli JM, Koshland D: DNA double-strand breaks trigger genome-wide sister-chromatid cohesion through Eco1 (Ctf7). Science 2007, 317:245-248

41. Heidinger-Pauli JM, Unal E, Koshland D: Distinct targets of the Eco1 acetyltransferase modulate cohesion in S phase and in response to DNA damage. Mol Cell 2009, 34:311-321.

42. Heidinger-Pauli JM, Unal E, Guacci V, Koshland D: The kleisin subunit of cohesin dictates damage-induced cohesion. Mol Cell 2008, 31:47-56.

43. Dodson H, Morrison CG: Increased sister chromatid cohesion and DNA damage response factor localization at an enzyme-induced DNA doublestrand break in vertebrate cells. Nucleic Acids Res 2009, 37:6054-6063.

44. Watanabe K, Pacher M, Dukowic S, Schubert V, Puchta H, Schubert I: The STRUCTURAL MAINTENANCE OF CHROMOSOMES 5/6 complex promotes sister chromatid alignment and homologous recombination after DNA damage in Arabidopsis thaliana. Plant Cell 2009, 21:2688-2699.

45. Kim BJ, Li Y, Zhang J, Xi Y, Yang T, Jung SY, Pan X, Chen R, Li W, Wang Y, et al: Genome-wide reinforcement of cohesin binding at pre-existing cohesin sites in response to ionizing radiation in human cells. J Biol Chem 2010, 285:22784-22792.

46. Yazdi PT, Wang Y, Zhao S, Patel N, Lee EY, Qin J: SMC1 is a downstream effector in the ATM/NBS1 branch of the human S-phase checkpoint. Genes Dev 2002, 16:571-582.

47. Kim ST, Xu B, Kastan MB: Involvement of the cohesin protein, Smc1, in Atm-dependent and independent responses to DNA damage. Genes Dev 2002, 16:560-570.

48. Garg R, Callens S, Lim DS, Canman CE, Kastan MB, Xu B: Chromatin association of rad17 is required for an ataxia telangiectasia and radrelated kinase-mediated S-phase checkpoint in response to low-dose ultraviolet radiation. Mol Cancer Res 2004, 2:362-369.

49. Kitagawa R, Bakkenist CJ, McKinnon PJ, Kastan MB: Phosphorylation of SMC1 is a critical downstream event in the ATM-NBS1-BRCA1 pathway. Genes Dev 2004, 18:1423-1438.

50. Luo H, Li Y, Mu JJ, Zhang J, Tonaka T, Hamamori Y, Jung SY, Wang Y, Qin J: Regulation of intra-S phase checkpoint by ionizing radiation (IR)dependent and IR-independent phosphorylation of SMC3. J Biol Chem 2008, 283:19176-19183

51. Watrin E, Peters JM: The cohesin complex is required for the DNA damage-induced G2/M checkpoint in mammalian cells. EMBO J 2009, 28:2625-2635.

52. Nagao K, Adachi Y, Yanagida M: Separase-mediated cleavage of cohesin at interphase is required for DNA repair. Nature 2004, 430:1044-1048.

53. Ono T, Losada A, Hirano M, Myers MP, Neuwald AF, Hirano T: Differential contributions of condensin I and condensin II to mitotic chromosome architecture in vertebrate cells. Cell 2003, 115:109-121.

54. Hirano T: Chromosome shaping by two condensins. Cell Cycle 2004, 3:26-28.

55. Csankovszki G, Collette K, Spahl K, Carey J, Snyder M, Petty E, Patel U, Tabuchi T, Liu H, McLeod I, et al: Three distinct condensin complexes control C. elegans chromosome dynamics. Curr Biol 2009, 19:9-19.

56. Aono N, Sutani T, Tomonaga T, Mochida S, Yanagida M: Cnd2 has dual roles in mitotic condensation and interphase. Nature 2002, 417:197-202.

57. Chen ES, Sutani T, Yanagida M: Cti1/C1D interacts with condensin SMC hinge and supports the DNA repair function of condensin. Proc Natl Acad Sci USA 2004, 101:8078-8083.

58. Heale JT, Ball AR Jr, Schmiesing JA, Kim JS, Kong X, Zhou S, Hudson DF, Earnshaw WC, Yokomori K: Condensin I interacts with the PARP-1-XRCC1 complex and functions in DNA single-strand break repair. Mol Cell 2006, 21:837-848.

59. Kong X, Stephens J, Ball AR Jr, Heale JT, Newkirk DA, Berns MW, Yokomori $\mathrm{K}$ : Condensin I recruitment to base damage-enriched DNA lesions is modulated by PARP1. PLoS One 2011, 6:e23548.

60. Wood JL, Liang Y, Li K, Chen J: Microcephalin/MCPH1 associates with the Condensin II complex to function in homologous recombination repair. J Biol Chem 2008, 283:29586-29592.
61. Tsang CK, Wei Y, Zheng XF: Compacting DNA during the interphase: condensin maintains rDNA integrity. Cell Cycle 2007, 6:2213-2218.

62. Tsang CK, Li H, Zheng XS: Nutrient starvation promotes condensin loading to maintain rDNA stability. EMBO J 2007, 26:448-458.

63. Tsang CK, Zheng XF: Opposing role of condensin and radiation-sensitive gene RAD52 in ribosomal DNA stability regulation. J Biol Chem 2009, 284:21908-21919.

64. Cabello OA, Eliseeva E, He WG, Youssoufian H, Plon SE, Brinkley BR, Belmont JW: Cell cycle-dependent expression and nucleolar localization of hCAP-H. Mol Biol Cell 2001, 12:3527-3537.

65. Uzbekov R, Timirbulatova E, Watrin E, Cubizolles F, Ogereau D, Gulak P, Legagneux V, Polyakov VJ, Le Guellec K, Kireev I: Nucleolar association of pEg7 and XCAP-E, two members of Xenopus laevis condensin complex in interphase cells. J Cell Sci 2003, 116:1667-1678.

66. Duan X, Yang Y, Chen YH, Arenz J, Rangi GK, Zhao X, Ye H: Architecture of the Smc5/6 Complex of Saccharomyces cerevisiae Reveals a Unique Interaction between the Nse5-6 Subcomplex and the Hinge Regions of Smc5 and Smc6. J Biol Chem 2009, 284:8507-8515.

67. Doyle JM, Gao J, Wang J, Yang M, Potts PR: MAGE-RING protein complexes comprise a family of E3 ubiquitin ligases. Mol Cell 2010, 39:963-974.

68. Potts PR, Yu H: Human MMS21/NSE2 is a SUMO ligase required for DNA repair. Mol Cell Biol 2005, 25:7021-7032.

69. Andrews EA, Palecek J, Sergeant J, Taylor E, Lehmann AR, Watts FZ: Nse2, a component of the Smc5-6 complex, is a SUMO ligase required for the response to DNA damage. Mol Cell Biol 2005, 25:185-196.

70. Zhao X, Blobel G: A SUMO ligase is part of a nuclear multiprotein complex that affects DNA repair and chromosomal organization. Proc Natl Acad Sci USA 2005, 102:4777-4782.

71. Nasim A, Smith BP: Genetic control of radiation sensitivity in Schizosaccharomyces pombe. Genetics 1975, 79:573-582.

72. Lehmann AR, Walicka M, Griffiths DJ, Murray JM, Watts FZ, McCready S, Carr AM: The rad18 gene of Schizosaccharomyces pombe defines a new subgroup of the SMC superfamily involved in DNA repair. Mol Cell Biol 1995, 15:7067-7080.

73. Taylor EM, Copsey AC, Hudson JJ, Vidot S, Lehmann AR: Identification of the proteins, including MAGEG1, that make up the human SMC5-6 protein complex. Mol Cell Biol 2008, 28:1197-1206.

74. Santa Maria SR, Gangavarapu V, Johnson RE, Prakash L, Prakash S: Requirement of Nse1, a subunit of the Smc5-Smc6 complex, for Rad52dependent postreplication repair of UV-damaged DNA in Saccharomyces cerevisiae. Mol Cell Biol 2007, 27:8409-8418.

75. Pebernard S, Perry JJ, Tainer JA, Boddy MN: Nse1 RING-like domain supports functions of the Smc5-Smc6 holocomplex in genome stability. Mol Biol Cell 2008, 19:4099-4109.

76. Pebernard S, Wohlschlegel J, McDonald WH, Yates JR, Boddy MN: The Nse5-Nse6 dimer mediates DNA repair roles of the Smc5-Smc6 complex. Mol Cell Biol 2006, 26:1617-1630.

77. Verkade HM, Bugg SJ, Lindsay HD, Carr AM, O'Connell MJ: Rad18 is required for DNA repair and checkpoint responses in fission yeast. $\mathrm{Mol}$ Biol Cell 1999, 10:2905-2918.

78. McDonald WH, Pavlova Y, Yates JR, Boddy MN: Novel essential DNA repair proteins Nse1 and Nse2 are subunits of the fission yeast Smc5-Smc6 complex. J Biol Chem 2003, 278:45460-45467.

79. Stephan AK, Kliszczak M, Dodson H, Cooley C, Morrison CG: Roles of vertebrate Smc5 in sister chromatid cohesion and homologous recombinational repair. Mol Cell Biol 2011, 31:1369-1381.

80. De Piccoli G, Cortes-Ledesma F, Ira G, Torres-Rosell J, Uhle S, Farmer S, Hwang JY, Machin F, Ceschia A, McAleenan A, et al: Smc5-Smc6 mediate DNA double-strand-break repair by promoting sister-chromatid recombination. Nat Cell Biol 2006, 8:1032-1034.

81. Mengiste T, Revenkova E, Bechtold N, Paszkowski J: An SMC-like protein is required for efficient homologous recombination in Arabidopsis. EMBO J 1999, 18:4505-4512.

82. Lindroos HB, Strom L, Itoh T, Katou $Y$, Shirahige $K$, Sjogren C: Chromosomal association of the Smc5/6 complex reveals that it functions in differently regulated pathways. Mol Cell 2006, 22:755-767.

83. Ampatzidou E, Irmisch A, O'Connell MJ, Murray JM: Smc5/6 is required for repair at collapsed replication forks. Mol Cell Biol 2006, 26:9387-9401.

84. Branzei D, Sollier J, Liberi G, Zhao X, Maeda D, Seki M, Enomoto T, Ohta K, Foiani M: Ubc9- and mms21-mediated sumoylation counteracts 
recombinogenic events at damaged replication forks. Cell 2006,

127:509-522.

85. Sheedy DM, Dimitrova D, Rankin JK, Bass KL, Lee KM, Tapia-Alveal C, Harvey SH, Murray JM, O'Connell MJ: Brc1-mediated DNA repair and damage tolerance. Genetics 2005, 171:457-468.

86. Lee KM, Nizza S, Hayes T, Bass KL, Irmisch A, Murray JM, O'Connell MJ: Brc1mediated rescue of $S m c 5 / 6$ deficiency: requirement for multiple nucleases and a novel Rad18 function. Genetics 2007, 175:1585-1595.

87. Chen YH, Choi K, Szakal B, Arenz J, Duan X, Ye H, Branzei D, Zhao X Interplay between the Smc5/6 complex and the Mph1 helicase in recombinational repair. Proc Natl Acad Sci USA 2009, 106:21252-21257.

88. Bermudez-Lopez M, Ceschia A, de Piccoli G, Colomina N, Pasero P, Aragon L, Torres-Rosell J: The Smc5/6 complex is required for dissolution of DNA-mediated sister chromatid linkages. Nucleic Acids Res 2010, 38:6502-6512.

89. Chavez A, George V, Agrawal V, Johnson FB: Sumoylation and the structural maintenance of chromosomes (Smc) 5/6 complex slow senescence through recombination intermediate resolution. J Biol Chem 2010, 285:11922-11930

90. Irmisch A, Ampatzidou E, Mizuno K, O'Connell MJ, Murray JM: Smc5/6 maintains stalled replication forks in a recombination-competent conformation. EMBO J 2009, 28:144-155.

91. Torres-Rosell J, Machin F, Farmer S, Jarmuz A, Eydmann T, Dalgaard JZ, Aragon L: SMC5 and SMC6 genes are required for the segregation of repetitive chromosome regions. Nat Cell Biol 2005, 7:412-419.

92. Torres-Rosell J, Machin F, Aragon L: Smc5-Smc6 complex preserves nucleolar integrity in S. cerevisiae. Cell Cycle 2005, 4:868-872.

93. Torres-Rosell J, Sunjevaric I, De Piccoli G, Sacher M, Eckert-Boulet N, Reid R, Jentsch S, Rothstein R, Aragon L, Lisby M: The Smc5-Smc6 complex and SUMO modification of Rad52 regulates recombinational repair at the ribosomal gene locus. Nat Cell Biol 2007, 9:923-931.

doi:10.1186/2045-3701-2-5

Cite this article as: Wu and Yu: The Smc complexes in DNA damage response. Cell \& Bioscience 2012 2:5.

\section{Submit your next manuscript to BioMed Central and take full advantage of:}

- Convenient online submission

- Thorough peer review

- No space constraints or color figure charges

- Immediate publication on acceptance

- Inclusion in PubMed, CAS, Scopus and Google Scholar

- Research which is freely available for redistribution

Submit your manuscript at www.biomedcentral.com/submit
Ciomed Central 